\title{
Preparation and therapeutic evaluation of rutin-phospholipid complex for antidiabetic activity
}

\author{
Rashmi Vankudri ${ }^{1}$, Prasanna Habbu ${ }^{2 *}$, Mahesh Hiremath ${ }^{2}$, B. S. Patil ${ }^{2}$, Chetan Savant ${ }^{3}$ \\ ${ }^{1}$ Faculty of Pharmacy, PRIST University, Thanjavur, Tamilnadu, India. ${ }^{2}$ Post graduate Department of Pharmacognosy and Phytochemistry, SET's College \\ of Pharmacy, Dharwad- 580002 Karnataka, India. ${ }^{3}$ Post graduate Department of pharmacology, SET's College of Pharmacy, Dharwad, Karnataka, India.
}

\begin{tabular}{|c|c|}
\hline ARTICLE INFO & ABSTRACT \\
\hline Article history: & \multirow{10}{*}{$\begin{array}{l}\text { The objective of the present work to prepare Rutin-phospholipid complex (RPC), a phytoformulation and } \\
\text { characterization, evaluation for its antidiabetic activity in streptozotocin induced diabetic model. Prepared RPC } \\
\text { was characterized and screened for antidiabetic activity by OGTT in normoglycemic and diabetic rats for RT and } \\
\text { RPC at different time intervals. Effect of RT and RPC ( } 50 \text { and } 100 \mathrm{mg} / \mathrm{kg} \text { b.w. p.o. respectively) in STZ induced } \\
\text { diabetic rats for one day and fifteen days was studied. This is followed by estimation of Estimation of SG, and } \\
\text { lipid parameters. Histopathology studies of pancreatic tissue and bioavailability studies of RT \& RPC were also } \\
\text { carried out. SEM data showed that RPC has irregular size vesicles consisting of phosphatidylcholine. RPC } \\
\text { showed a single endothermal peak at } 147.68^{\circ} \mathrm{C} \text { in DSC studies. OH group has shifted to lower frequency in } \\
\text { phytosome compared to rutin phospholipid in FTIR spectra. Treatment with RPC ( } 50 \text { and } 100 \mathrm{mg} / \mathrm{kg} \text { b.w. p.o.) } \\
\text { significantly reduced the blood glucose levels and restored the altered lipid parameters as compared to RT. } \\
\text { Histopathological studies revealed that RPC also restored back the size of pancreatic islets and maintained the } \\
\text { normal } \beta \text {-cells. A higher serum concentration of RT ( } 13.20 \mu \mathrm{g} / \mathrm{mL} \text { ) in RPC treated group was observed in } \\
\text { bioavailability studies as compared to RT. RPC maintained effective concentration of rutin for a longer period in } \\
\text { rat serum. }\end{array}$} \\
\hline Received on: 21/07/2015 & \\
\hline Revised on: 03/09/2015 & \\
\hline Accepted on: 29/10/2015 & \\
\hline Available online: $26 / 01 / 2016$ & \\
\hline Key words: & \\
\hline Rutin phosoholipid complex, & \\
\hline antidiabetic activity, OGTT, & \\
\hline bioavailability. & \\
\hline & \\
\hline
\end{tabular}

\section{INTRODUCTION}

Diabetes mellitus (DM) is a metabolic disease in which there are high blood sugar levels over a prolonged period. It leads to decrease in both insulin secretion and insulin action. It is associated with the development of vascular diseases which include neuropathy, nephropathy, cardiovascular and cerebrovascular diseases (Rao et al., 2010). The world wide prevalence of diabetes for all age groups is projected to rise from 382 million in 2013 to 592 million in 2035 (Guariguata et al., 2014).

Presently, the growing interest in herbal remedies is associated with the oral hypoglycemic agents for treatment of DM. So, the traditional medicines obtained from the plants play an important role in the management of diabetes mellitus. The active constituents of plants are either polar or water soluble. The water soluble phytoconstituents as flavanoids, tannins,

\footnotetext{
* Corresponding Author

Prasanna Habbu, Post graduate Department of Pharmacognosy and Phytochemistry, SET's College of Pharmacy, Dharwad 580002

Karnataka, India. Email: prasherbs@yahoo.com
}

polyphenols etc. are poorly absorbed due to their poor lipid solubility and large molecular size. So, the ability to transport across lipid membranes results in poor bioavailability (Kidd, 2009). Bio-flavanoids consists of a group of polyphenolic secondary plant metabolites that are wide spread in nature containing a unique C6-C3-C6 structure. Flavanoids that have well categorized structure function relationships are: flavans, flavanones, flavones, flavanols, flavanonols, catechins, anthocyanidins and isoflavones. Bio-flavanoids are having wellknown multidirectional biological activities including antidiabetic efficacy (Goutam, 2011).

Phytosome is a patented technology which is used to increase absorption and bioavailability. A phytoformulation obtained by incorporation of standardized plant extracts or water soluble phytoconstituents into phospholipids to produce lipid compatible molecular complexes is termed as a phytosome (Yang et al., 2005). Rutin, a very common quercetin glycoside was recognized to decrease the permeability of capillaries; it has also been reported to scavenge free radical, to lower hepatic cholesterol levels, showed antiplatelet activity and antidiabetic activity (Yang et al., 2005). 
As the efficacy of any herbal formulation depends on the concentration of the active compound and cell membranes are made up of phospholipids, an effort has been made in the present study to prepare, characterize and to evaluate phospholipid complex of rutin (RT) for antidiabetic effect to substantiate the claim that complexation between standard rutin and phospholipid can enhance the therapeutic efficacy of the parent molecule along with bioavailability studies in rats.

\section{MATERIALS AND METHODS}

\section{Materials}

Standard Rutin was obtained as a gift sample from Shreya Life Sciences Pvt Ltd. Waluj, Aurangabad, Maharashtra, India. Qualitative analysis of sample was confirmed by HPLC and FTIR analysis. Hydrogenated soya phosphatidyl choline (HSPC) and Streptozotocin (STZ) purchased from Hi-media, Mumbai. Standard drug Glibenclamide (GLB) was obtained from Aventis pharma Ltd.

\section{Preparation of rutin phospholipid complex (RPC)}

RT and HSPC were refluxed with $30 \mathrm{~mL}$ of dichloromethane at a temperature not exceeding $60^{\circ} \mathrm{C}$ for $3 \mathrm{~h}$ in a $100 \mathrm{~mL}$ round bottom flask. The mixture was then concentrated to 5-10 mL. To the concentrated mixture $30 \mathrm{~mL}$ of $\mathrm{n}$-hexane was added carefully with continuous stirring to get the precipitate. The precipitate was filtered and stored in vacuum desiccator for overnight. The dried precipitate was crushed in mortar and sieved in \#100 mesh. Powdered complex was kept in amber colored bottle flushed with nitrogen and stored at room temperature (Prasanna et al., 2013).

\section{Physicochemical properties of RPC \\ Microscopic view}

Trinocular microscope (LX 300, LABOMED Inc, USA) was used for characterization of the complex. The complex was suspended in distilled water and a drop was placed on a slide and covered with a cover slip. Microscopic view of complex was observed at a magnification of 100x, 200x and 400x (Prasanna et al., 2013)

\section{Scanning electron microscopy (SEM)}

Scanning electron microscopy (JOEL JSM-6360 scanning microscope Japan) has been used to determine the particle size distribution and surface morphology. Samples were placed on an electron microscope brass stub and coated with gold in an ion sputter. Photographs of RT, RPC and physical mixture of $\mathrm{RT}$ and RPC were taken by random scanning of the stub at $100 \mathrm{x}$, 500x and 1000x magnifications (Prasanna et al., 2013).

\section{Differential scanning colourimetry (DSC)}

$\mathrm{RT}, \mathrm{RPC}$, and physical mixture of RT and RPC were placed in the aluminum crimp cell and heated at $10^{\circ} \mathrm{C} / \mathrm{min}$ from 0 to $400^{\circ} \mathrm{C}$ in an atmosphere of nitrogen (TA instruments USA, model DSC Q10 V24 4 build 116). Peak transition onset temperatures were recorded by means of an analyzer (Prasanna et al., 2013).

\section{FTIR}

FTIR ( $\alpha$-series, Bruker, Germany) spectral data were taken to ascertain the structure and chemical stability of RPC, phosphatidylcholine and RT. Samples were crushed with $\mathrm{KBr}$ to get pellets at $600 \mathrm{~kg} / \mathrm{cm}^{2}$ pressure. Spectral scanning was done in the range between 4000 and $500 \mathrm{~cm}^{-1}$ (Prasanna et al., 2013).

\section{Apparent solubility}

Solubility determination of rutin material and phospholipid complex was carried out by adding excess of rutin material and phospholipids complex to $6 \mathrm{~mL}$ of water or $n$-octanol in sealed glass containers at $25{ }^{\circ} \mathrm{C}$. Each experiment was performed in triplicate.

The liquids were agitated for $24 \mathrm{~h}$, then centrifuged to remove excessive rutin $(15-20 \mathrm{~min}, 4000 \mathrm{rpm})$. The supernatant was filtered through a $0.45 \mu \mathrm{m}$ membrane. The $1 \mathrm{~mL}$ filtrate was mixed with $9 \mathrm{~mL}$ of solvent $\mathrm{A}$ and a $20 \mu \mathrm{L}$ aliquot of the resulting solution was injected into a HPLC and detected at a wavelength of $340 \mathrm{~nm}$, the concentration of rutin was measured (Yanyu et al., 2006).

\section{Determination of content of RT in RPC by HPLC}

The content of RT in RPC was determined using HPLC. About $50 \mathrm{mg}$ of RT/RPC was placed into $50 \mathrm{~mL}$ volumetric flask. $35 \mathrm{~mL}$ of methanol was added and mixed on cyclomixer for $5 \mathrm{~min}$, and sonicated to dissolve for $10 \mathrm{~min}$. Final volume was made with methanol and a $20 \mu \mathrm{L}$ aliquot of the resulting solution was injected into Shimadzu LC-2010 HPLC system.

The stationary phase, hypersil ODS, C-18 $250 \mathrm{~mm} \times 4.6$ $\mathrm{mm}, 5 \mu \mathrm{m}$ was kept at $25^{\circ} \mathrm{C}$. The mobile phase was a mixture of $5 \%$ phosphoric acid: acetonitrile: methanol (60:30:10). The flow rate was $1.5 \mathrm{~mL} / \mathrm{min}$. Effluent was monitored at $340 \mathrm{~nm}$ (Maiti et al., 2007).

\section{Dissolution studies}

The dissolution studies were carried out according to a dissolution test apparatus (paddle method). The dissolution flasks were immersed in a water bath at $37^{\circ} \mathrm{C}$. The dissolution medium (pH $1.2 \mathrm{HCl}$ or $\mathrm{pH} 6.8$ phosphate buffer saline, $900 \mathrm{~mL}$ ) was continuously stirred at $100 \mathrm{rpm}$. RPC which is equivalent to 185 $\mathrm{mg}$ of rutin was added on the surface of the stirred dissolution medium at the beginning of the study.

At different time intervals, $10 \mathrm{~mL}$ samples were withdrawn and filtered using cellulose nitrate membrane, $10 \mathrm{~mL}$ fresh mediums were added into the flask. The $1 \mathrm{~mL}$ filtrate was mixed with $9 \mathrm{~mL}$ of solvent $\mathrm{A}$ and a $20 \mu \mathrm{L}$ aliquot of the resulting solution was injected onto a HPLC and detected at a wavelength of $340 \mathrm{~nm}$, the concentration of rutin was measured (Maiti et al., 2007). 


\section{Screening of RPC for antidiabetic activity Animals}

Male Wistar rats weighing 190-210 g were used for the present study. The animals were purchased from Sri Venkateshwara Enterprises, Bangalore, India. They were maintained in the animal house of SET's College of Pharmacy, Dharwad, India for experimental purpose. The animals were maintained under controlled conditions of temperature $\left(22 \pm 2^{\circ} \mathrm{C}\right)$, humidity $(50 \pm 5 \%)$ and $12 \mathrm{~h}$ light-dark cycles. They were fed commercial stock diet and water, ad libitum. The animals were housed individually in sanitized polypropylene cages containing sterile paddy husk as bedding.

Animals were habituated to laboratory conditions for $48 \mathrm{~h}$ prior to experimental protocol to minimize if any of non-specific stress. All the studies conducted were approved by the Institutional Animal Ethical Committee (IAEC) of SET's College of Pharmacy, Dharwad, India.

\section{Effect of RPC in normoglycemic rats \\ Oral glucose tolerance (OGTT) in normal rats}

The OGTT was performed in overnight-fasted (18h) normal rats. The experimental rats were divided into six groups of six each and treated as follows:

Group 1: Normal control (NC) received water $(10 \mathrm{~mL} / \mathrm{kg}$, p.o. $)$

Group 2: NC rats treated with glibenclamide $(0.5 \mathrm{mg} / \mathrm{kg}$, p.o. $)$

Group 3: NC rats treated with RT (50 mg/kg, p.o.)

Group 4: NC rats treated with RT (100 mg/kg, p.o.)

Group 5: NC rats treated with RPC (50mg/kg, p.o.)

Group 6: NC rats treated with RPC (100 mg/kg, p.o.)

All the rats were fasted for $18 \mathrm{~h}$ and given different doses of RT, RPC, glibenclamide (GLB) and vehicle orally. After 30 min glucose $(2 \mathrm{gm} / \mathrm{kg}$ in distilled water) was administered orally. Blood samples were collected before glucose load ( $0 \mathrm{~min})$ and 30 , 60 and $120 \mathrm{~min}$ afterwards. Serum glucose (SG) levels were estimated using a glucose oxidase-peroxidase reactive strips and a glucometer (SD Check Gold Blood Glucose Meter, Standard Diagnostics, Korea). The results were expressed as integrated area under curve for glucose $\left(\mathrm{AUC}_{\text {glucose }}\right)$ by trapezoid rule (Shirwaikar et al., 2006).

\section{Effect of RT and RPC in STZ-induced diabetic rats Induction of diabetes mellitus (DM)}

Diabetes was induced by single intravenous injection of streptozotocin (STZ) $(45 \mathrm{mg} / \mathrm{kg}$ ). STZ was dissolved in ice-cold citrate buffer $(\mathrm{pH}-4.5)$ and injected immediately within few minutes to avoid degradation. Rats were provided with $10 \%$ glucose solution after $6 \mathrm{~h}$ of STZ administration for the next $24 \mathrm{~h}$ to prevent hypoglycemia as STZ is capable of inducing fatal hypoglycemia as a result of massive pancreatic insulin release. Blood samples were collected $48 \mathrm{~h}$ later, and SG levels were determined to confirm the development of diabetes. Only those animals which showed blood glucose level more than $250 \mathrm{mg} / \mathrm{dL}$ were used for the experiment (Muruganandan et al., 2005).
Diabetic rats were randomized into different groups based on their SG levels.

\section{Experimental design for Single-dose one-day study}

The experimental rats were divided into seven groups of six each and treated as follows

Group 1: Normal control (NC) received water $(10 \mathrm{~mL} / \mathrm{kg}$, p.o.)

Group 2: Diabetic control (DC) received water (10 mL/kg, p.o.)

Group 3: DC rats treated with glibenclamide $(0.5 \mathrm{mg} / \mathrm{kg}$, p.o.)

Group 4: DC rats treated with RT (50 mg/kg, p.o.)

Group 5: DC rats treated with RT (100 mg/kg, p.o.)

Group 6: DC rats treated with RPC (50 mg/kg, p.o.)

Group 7: DC rats treated with RPC (100 mg/kg, p.o.)

Blood samples were collected at 0,2 and $4 \mathrm{~h}$ after RT, RPC and GLB administration. SG was estimated by using a glucose oxidase-peroxidase reactive strips and a glucometer. Percent reduction in glycemia was calculated with respect to the initial $(0 \mathrm{~h})$ level according to: Percentage reduction in glycemia $=[(\mathrm{Gi}-\mathrm{Gt}) / \mathrm{Gi}] \times 100$; where Gi is initial glycemia and Gt is glycemia at 2 and $4 \mathrm{~h}$.

\section{Experimental design for Multiple-dose fifteen-day study}

The animals were treated with respective doses of RT, RPC and GLB for 15 consecutive days (Kumar et al., 2006) and SG were measured as explained above using glucometer.

Group 1: Normal control (NC) received water $(10 \mathrm{~mL} / \mathrm{kg}$, p.o. $)$

Group 2: Diabetic control (DC) received water $(10 \mathrm{~mL} / \mathrm{kg}$, p.o.)

Group 3: DC rats treated with glibenclamide $(0.5 \mathrm{mg} / \mathrm{kg}$, p.o.)

Group 4: DC rats treated with RT (50 mg/kg, p.o.)

Group 5: DC rats treated with RT (100 mg/kg, p.o.)

Group 6: DC rats treated with RPC (50 mg/kg, p.o.)

Group 7: DC rats treated with RPC (100 mg/kg, p.o.)

\section{OGTT in diabetic rats}

At the end of 15 days of treatment, glucose $(2 \mathrm{~g} / \mathrm{kg}$ body weight) was administered to $12 \mathrm{~h}$ fasted rats and blood samples were collected at 0 (immediately after glucose load), 30, 60 and $120 \mathrm{~min}$ after glucose administration. Glucose was estimated and results were expressed as integrated area under curve for glucose $\left(\mathrm{AUC}_{\mathrm{glucose}}\right)$ calculated by trapezoid rule (Liu et al., 2005).

\section{Estimation of biochemical parameters}

At the end of the treatment, blood samples were collected from retro-orbital plexus. Serum was separated and analysed spectrophotometrically for triglycerides (TG), total cholesterol (TC), HDL-cholesterol (HDL-c) using diagnostic reagent kit ERBA diagnostics Mannheim GMBH, Germany. VLDL-c, LDL-c in serum were calculated as per Friedewald's equation (Friedewald et al., 1972).

$$
(\text { VLDL-c })=\frac{\text { Triglyceride }}{5}
$$

LDL-c $=$ Total cholesterol- $\underline{\text { Triglyceride }- \text { HDL-c }}$ 
The markers of dyslipidemia such as TC/HDL-c \& LDL-c/HDL-c ratios were also calculated.

\section{Histopathological examination}

Pancreas of individual animal were excised quickly, fixed in $10 \%$ buffered neutral formalin, and fixed in bovine solution. They were further processed for paraffin embedding following standard microtechnique. Sections were stained with alum-haematoxylin and eosin, were observed photomicroscopically for histopathological changes (Galigher, 1971).

\section{Bioavailability experiments in rats}

\section{Serum sample preparation}

Twelve wistar albino male rats were divided into two groups and fasted for $12 \mathrm{~h}$, but allowed to take up water freely. RT and RPC equivalents to $40 \mathrm{mg} / \mathrm{kg}$ were suspended into distilled water and Tween $20 \%$ and administered orally to rats. The rats were anesthetized with ether and $500 \mu \mathrm{L}$ blood was withdrawn from retro-orbital plexus in heparin tubes at an interval of $0,1,2$, $3,4,5 \mathrm{~h}$

The blood was centrifuged at $3000 \mathrm{rpm}$ for $10 \mathrm{~min}$ and plasma was separated. $10 \mu \mathrm{L}$ of aliquot was taken into $10 \mathrm{~mL}$ volumetric flask; methanol was added to transferred to $15 \mathrm{~mL}$ volumetric centrifuged at $5000 \mathrm{rpm}$ for $10 \mathrm{~min}$. the supernatant liquid was used to estimate the content of rutin by HPLC.

\section{Estimation of rutin content in serum}

The serum concentration of rutin was determined by HPLC (Shimadzu LC-2010, Japan) system. The stationary phase, Hypersil ODS, C-18 $250 \mathrm{~mm} \times 4.6 \mathrm{~mm}, 5 \mu \mathrm{m}$ was kept at $25^{\circ} \mathrm{C}$. The mobile phase was a mixture of $5 \%$ phosphoric acid: acetonitrile: methanol (60:30:10). The flow rate was $1.5 \mathrm{~mL} / \mathrm{min}$. Effluent was monitored at $340 \mathrm{~nm}$ and peaks were noted down (Prasanna et al., 2013).

\section{Statistical evaluation}

The data were expressed as Mean \pm S.E.M. Statistical comparisons were performed by one-way ANOVA followed by Tukey's post-test. $\mathrm{P}<0.05$ were considered was considered significant.

\section{RESULTS}

Preparation of rutin phospholipid complex

Rutin phospholipid complex was prepared according to different quantity ratio of phospholipids and drugs.

The results showed that when the ratio was less than 1 , the stability of phospholipid complexes was worse, when the ratio was more than 1 the appearance of resultant material was viscous and we prepared rutin phospholipid complex in terms of the quantity ratio 1 the content of RT in the phospholipids complex was $53.17 \% \mathrm{w} / \mathrm{w}$.

\section{Physicochemical properties of rutin phospholipid complex Microscopic view}

The surface morphology of the RPC at various magnifications showed that the drug particles are associated with the phospholipid forming the complexes with irregular size. The microscopic view indicated the presence of spherical structures of the complex. The spherical structures consisted of HSPC and RT which was seen to be interpolated between the lipid layers.

\section{Scanning electron microscopy (SEM)}

The surface morphology of RPC as examined by SEM is shown in Figure 1. RPC was appeared as irregular shape. We could see that phospholipids did not exit on the appearance of drugs but RT was uniformly dispersed in phospholipids and formed the structure of irregular shape.


Fig. 1: Scanning electron microscopy (SEM) surface morphology and particle size distribution of RPC (SEM) at A) 200X, B) $2000 \mathrm{X}$ and C) $5000 \mathrm{X}$ magnifications. RT was found to be intercalated within the lipid layers.

\section{Differential scanning colourimetry (DSC)}

DSC is a reliable method to screen drug excipient compatibility and provides maximum information about the possible interactions. In DSC, we can conclude the interaction by 
elimination of endothermic peak (s), appearance of new peak (s) area, change in the peak shape and its onset, peak temperature/ melting point and relative peak area. Figure 2 shows the DSC thermograms of phospholipid (A), pure rutin (B), rutin phospholipid complex (C) and physical mixture of rutin and phospholipid (D).

The DSC thermogram of Phospholipid showed a two peak, the first endothermal peak was milder and was considered that the formation of this peak was due to hot movements of phospholipid molecules to polarity parts.

The second endothermal peak at $159.4^{\circ} \mathrm{C}$ appears pointed. RT shows a endothermal peak at $181.03^{\circ} \mathrm{C}$, the physical mixture of RT and PC shows two endothermal peaks at $150.76^{\circ} \mathrm{C}$ and $173.42^{\circ} \mathrm{C}$. Further RPC showed a broad endothermal peak at $147.68^{\circ} \mathrm{C}$ which was more or less than physical mixture $\left(150.76^{\circ} \mathrm{C}\right)$. Therefore it can be concluded that RT molecules were dissolved in the phospholipids and formed the complex when the temperature was increased. This could be explained through the theory of preparation by melt-out method.

\section{FTIR}

The FTIR spectroscopy revealed shifting of hydroxyl $(\mathrm{OH})$ group to a lower frequency in the RPC spectra as compared to that of RT, indicating the formation of strong hydrogen bonding between hydroxyl groups of the phospholipids and rutin constituents in the phytosome form.

\section{Solubility studies}

The solubility of RT, physical mixture, and RPC in water or n-octanol was studied. The data shows that solubility of RPC in n-octanol was more than in water Table 1.

\section{Determination of content of RT in RPC by HPLC}

Figure 3 (A) and (B) showed the HPLC chromatograms of pure RT and RPC respectively. Content of rutin in the complex was estimated by HPLC and was found to be $53.17 \%$

\section{Dissolution studies}

Figure 4 shows the dissolution profile of rutin from rutin phospholipid complex and rutin in $\mathrm{HCl}(\mathrm{pH}$ 1.2) and phosphate buffer saline ( $\mathrm{pH} 6.8$ ), respectively. The dissolution of rutin from phospholipid complex in $\mathrm{pH} 6.8$ phosphate buffer saline was not complete until $60 \mathrm{~min}$; The amount about $167.8 \mathrm{mg}$; however at about $30 \mathrm{~min}$, the dissolution in $0.1 \mathrm{~N} \mathrm{HCl}$ was complete and the amount only $7.8 \mathrm{mg}$. The dissolution procedures are greatly influenced by the $\mathrm{pH}$ of media, and the dissolution amount of rutin was increased with increase in $\mathrm{pH}$ of media.
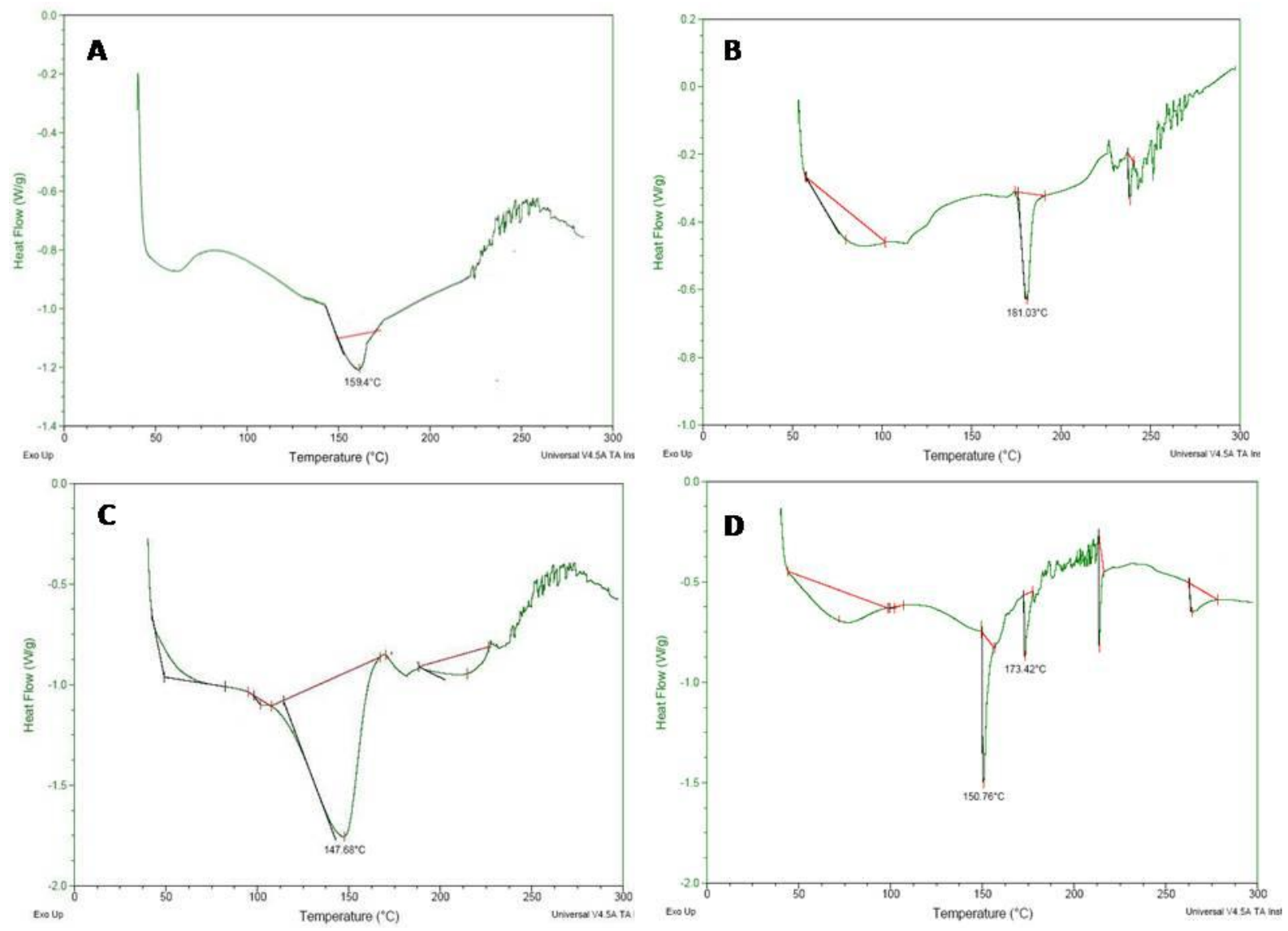

Fig. 2: Differential scanning colourimetry (DSC) of A) HSPC, B) Rutin, C) RPC and D) Physical mixture of RT \& RPC 
$\mathrm{mV}$

Chromatogram

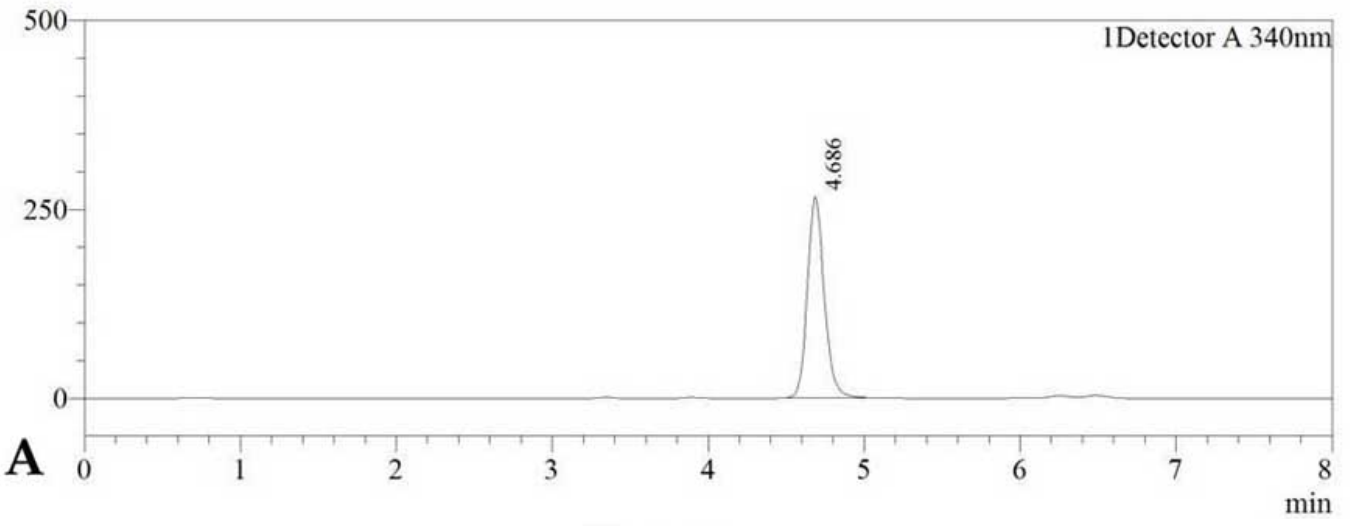

$\mathrm{mV}$

Chromatogram

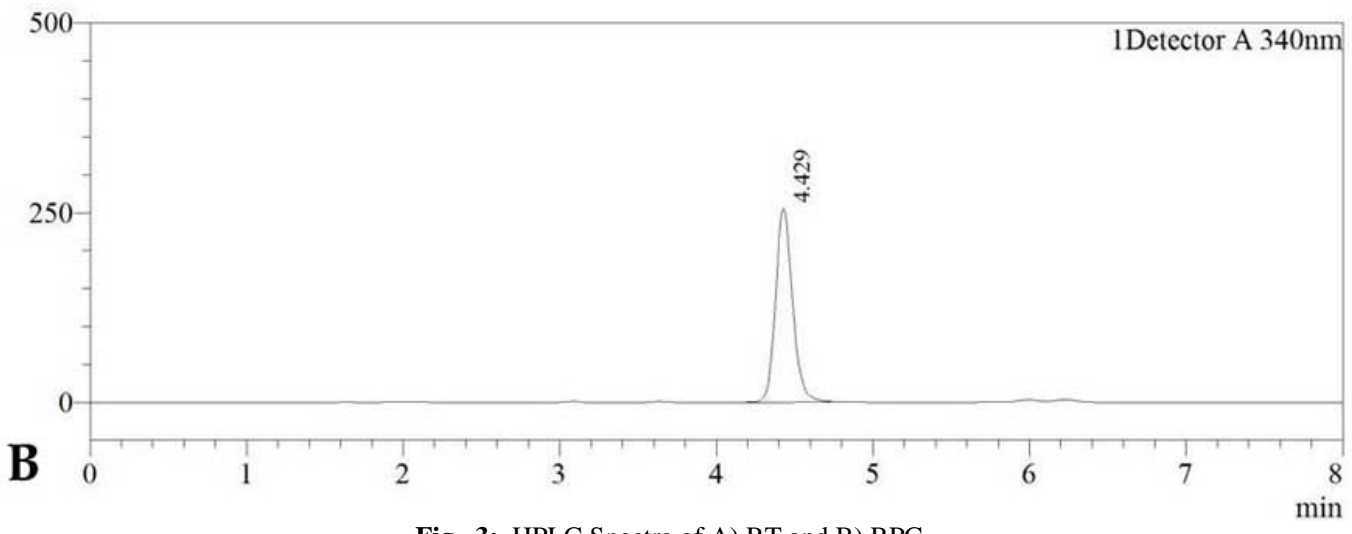

Fig. 3: HPLC Spectra of A) RT and B) RPC.



Fig. 4: Dissolution studies of different phytosome formulations. 
Table 1: Apparent solubility of RT and RPC in n-octanol and water at $25^{\circ} \mathrm{C}$.

\begin{tabular}{|c|c|c|c|c|c|c|c|c|}
\hline \multirow{3}{*}{ Sample } & \multirow{2}{*}{\multicolumn{3}{|c|}{$\begin{array}{c}\text { Apparent solubility in n-octanol at } \\
\qquad 25^{\circ} \mathrm{C}(\mu \mathrm{g} / \mathrm{ml})\end{array}$}} & \multirow{3}{*}{$\overline{\mathbf{x}} \pm \mathbf{S}$} & \multirow{2}{*}{\multicolumn{3}{|c|}{$\begin{array}{c}\text { Apparent solubility } \\
\text { in water at } 25^{\circ} \mathrm{C} \quad(\mu \mathrm{g} / \mathrm{ml})\end{array}$}} & \multirow{3}{*}{$\overline{\mathbf{x}} \pm \mathbf{s}$} \\
\hline & & & & & & & & \\
\hline & I & II & III & & I & II & III & \\
\hline Rutin (RT) & 20.32 & 21.65 & 21.98 & $21.32 \pm 0.507$ & 1.97 & 1.77 & 1.78 & $1.846 \pm 0.662$ \\
\hline Physical mixture & 36.56 & 35.11 & 36.00 & $35.89 \pm 0.422$ & 8.45 & 7.39 & 8.11 & $7.983 \pm 0.312$ \\
\hline Rutin phospholipid complex (RPC) & 58.27 & 56.75 & 58.19 & $57.74 \pm 0.493$ & 46.33 & 47.78 & 47.03 & $47.05 \pm 0.418$ \\
\hline
\end{tabular}

Table 2: Effect of RT and RPC on lipid profile in STZ induced diabetic rats.

\begin{tabular}{|c|c|c|c|c|c|c|c|}
\hline Serum parameter & $\begin{array}{l}\text { Normal } \\
\text { control }\end{array}$ & $\begin{array}{l}\text { Diabetic } \\
\text { control }\end{array}$ & Glibenclamide & RT 50mg/kg & RT $100 \mathrm{mg} / \mathrm{kg}$ & $\begin{array}{c}\mathrm{RPC} \\
50 \mathrm{mg} / \mathrm{kg}\end{array}$ & $\begin{array}{c}\mathrm{RPC} \\
100 \mathrm{mg} / \mathrm{kg}\end{array}$ \\
\hline STG(mg/dl) & $105.7 \pm 2.397$ & $212.2 \pm 3.850$ & $132.5 \pm 6.760 * * *$ & $188 \pm 5.050^{* *}$ & $163.5 \pm 3.865^{*}$ & $192.8 \pm 2.392 * * *$ & $172.2 \pm 2.702^{* * *}$ \\
\hline STC & $74.95 \pm 1.487$ & $124.4 \pm 4.17$ & $94.28 \pm 2.71 * * *$ & $108.7 \pm 3.54 * *$ & $104.6 \pm 2.54 * *$ & $108.5 \pm 3.211^{* *}$ & $104.1 \pm 2.141$ *** \\
\hline HDL-c & $30.51 \pm 1.184$ & $21.62 \pm 0.600$ & $41.30 \pm 0.608 * * *$ & $32.88 \pm 2.149 * *$ & $37.26 \pm 1.242 * * *$ & $29.78 \pm 1.450 * * *$ & $33.89 \pm 1.430 * * *$ \\
\hline VLDL-c & $21.14 \pm 0.479$ & $42.44 \pm 0.716$ & $26.49 \pm 1.352 * * *$ & $37.60 \pm 1.010 * *$ & $32.70 \pm 0.772 * * *$ & $38.55 \pm 0.478^{*}$ & $34.54 \pm 1.478^{* * *}$ \\
\hline LDL_c & $23.30 \pm 2.581$ & $60.83 \pm 4.409$ & $26.49 \pm 2.471 * * *$ & $40.33 \pm 2.043 * * *$ & $34.66 \pm 2.849 * * *$ & $40.16 \pm 3.728 * * *$ & $35.54 \pm 1.478^{* * *}$ \\
\hline TC/HDL-c ratio & $2.470 \pm 0.123$ & $5.776 \pm 0.246$ & $2.287 \pm 0.087 * * *$ & $3.354 \pm 0.164 * * *$ & $2.820 \pm 0.097 * * *$ & $3.689 \pm 0.219^{* * *}$ & $3.094 \pm 0.112 * * *$ \\
\hline LDL-c/HDL-c ratio & $0.780 \pm 0.108$ & $2.805 \pm 0.227$ & $0.644 \pm 0.067 * * *$ & $1.248 \pm 0.088^{* * *}$ & $0.950 \pm 0.081 * * *$ & $1.376 \pm 0.164 * * *$ & $1.061 \pm 0.072 * * *$ \\
\hline
\end{tabular}

The values are expressed as mean \pm SEM $(\mathrm{n}=6){ }^{*} \mathrm{P}<0.05,{ }^{* *} \mathrm{P}<0.01,{ }^{* * * *} \mathrm{P}<0.001$ as compared to diabetic control group.

\section{Screening of RPC for Antidiabetic activity Effect of RPC in normoglycemic rats OGTT in normal rats}

Administration of glucose produces a significant change in SG level of normal rats. Treatment with higher dose of RT (100 $\mathrm{mg} / \mathrm{kg})$ and RPC $(50 \mathrm{mg} / \mathrm{kg}$ and $100 \mathrm{mg} / \mathrm{kg})$ and GLB $(0.5 \mathrm{mg} / \mathrm{kg})$ significantly $(\mathrm{P}<0.01, \mathrm{P}<0.001)$ improved the glucose tolerance whereas, treatment with lower dose of RT $(50 \mathrm{mg} / \mathrm{kg})$ did not significantly reduced the $\mathrm{AUC}_{\text {glucose }}$ compared to the normal control group. The results are shown in Figure. 5 (A) and (B).

\section{Effect of RPC on STZ-induced diabetes in rats \\ Single dose single day study}

Acute hypoglycemic effect of RT and RPC was assessed in STZ- induced diabetic rats. A single dose of RT (50 and 100 $\mathrm{mg} / \mathrm{kg}$ ) and RPC (50 and $100 \mathrm{mg} / \mathrm{kg}$ ) treatment exhibited reduction in SG levels at different time intervals compared to basal levels $(0 \mathrm{~h})$. Also administration of GLB showed significant $(\mathrm{P}<0.001)$ reduction in $\mathrm{SG}$ levels with maximum reduction $(35.42 \%)$ at 4 h post GLB treatment compared to their basal levels, whereas, RT and RPC treated animals showed dose dependent percentage reduction in SG levels compared to their basal levels. (Figure 6)

\section{Effect of RPC on STZ-induced diabetes in rats Multiple dose fifteen day study}

Repeated administration of RT (50 and $100 \mathrm{mg} / \mathrm{kg}$ ) and RPC (50 and $100 \mathrm{mg} / \mathrm{kg}$ ) for 15 days showed significantly $(\mathrm{P}<0.05$, $\mathrm{P}<0.001)$ reduced levels of $\mathrm{SG}$ compared to the basal values $(0$ day). On $15^{\text {th }}$ day tested doses of RT and RPC showed significantly $(\mathrm{P}<0.001)$ greater percentage reduction $(34.22 \%$, $41.21 \%, 32.67 \%$ and $39.09 \%$ ) in glycemia compared to diabetic control. (Figure 7)

\section{OGTT in diabetic rats}

On $15^{\text {th }}$ day of the treatment, oral administration of glucose $(2 \mathrm{gm} / \mathrm{kg})$ did not produce significant change in SG level of normal control rats and AUC for the 120 min interval was not altered. As depicted in Figure 8 (A), the diabetic rats exhibited marked elevation in fasting SG level $(0 \mathrm{~h})$ and showed significant impairment in glucose tolerance to exogenous administration of glucose compared to normal control rats.

Treatment of diabetic rats with RPC $(50 \mathrm{mg} / \mathrm{kg}, 100$ $\mathrm{mg} / \mathrm{kg})$ and GLB $(0.5 \mathrm{mg} / \mathrm{kg})$ significantly $(\mathrm{P}<0.001)$ improved glucose tolerance and marked fall in SG level over the period of 120 min compared to diabetic control group. Figure 8 (B), shows the integrated $\mathrm{AUC}_{\text {glucose }}$ for the fraction. $\mathrm{AUC}_{\text {glucose }}$ for RPC (50 $\mathrm{mg} / \mathrm{kg}, 100 \mathrm{mg} / \mathrm{kg}$ ) and GLB was found to be significant $(\mathrm{P}<0.001)$ over the period of $120 \mathrm{~min}$. Collectively, RPC (50 $\mathrm{mg} / \mathrm{kg} \& 100 \mathrm{mg} / \mathrm{kg}$ ) showed marked improvement in glucose tolerance.

\section{Estimation of lipid parameter}

Diabetic rats showed significantly $(P<0.001)$ increased levels of STG, STC, VLDL-c and LDL-c levels, whereas HDL-c was decreased in diabetic rats compared to normal rats (Table 2). The markers of dyslipidemia such as Tc/HDL-c and LDL-c/HDL-c ratios were significantly elevated in diabetic group. Oral administration of different doses of rutin $(50 \&$ $100 \mathrm{mg} / \mathrm{kg}$ ) and rutin phospholipid complex (50 \& $100 \mathrm{mg} / \mathrm{kg}$ ) for 15 days exhibited significant reduction $(\mathrm{P}<0.001)$ in all tested lipid parameters and restoring them to near normal values.

\section{Histopathological examination}

Figure 9 shows the histomorphological changes in pancreas of different groups of animals. Hitopathological examination of pancreas from normal control group showed normal pancreatic acini and islet of langerhans with normal cellularity (Figure 9 A) whereas, decreased in number and size of pancreatic islets, vacuolation, hydropic and necrotic cells, degranulation of cells (Figure 9 B).Both RT and RPC (Figure 9 D and $\mathrm{E}$ respectively) and GLB (Figure $9 \mathrm{C}$ ) markedly showed to amend the disrupted islets of langerhans of diabetic rats; islets architecture and integrity were improved. Also number and size of pancreatic islets were increased. 


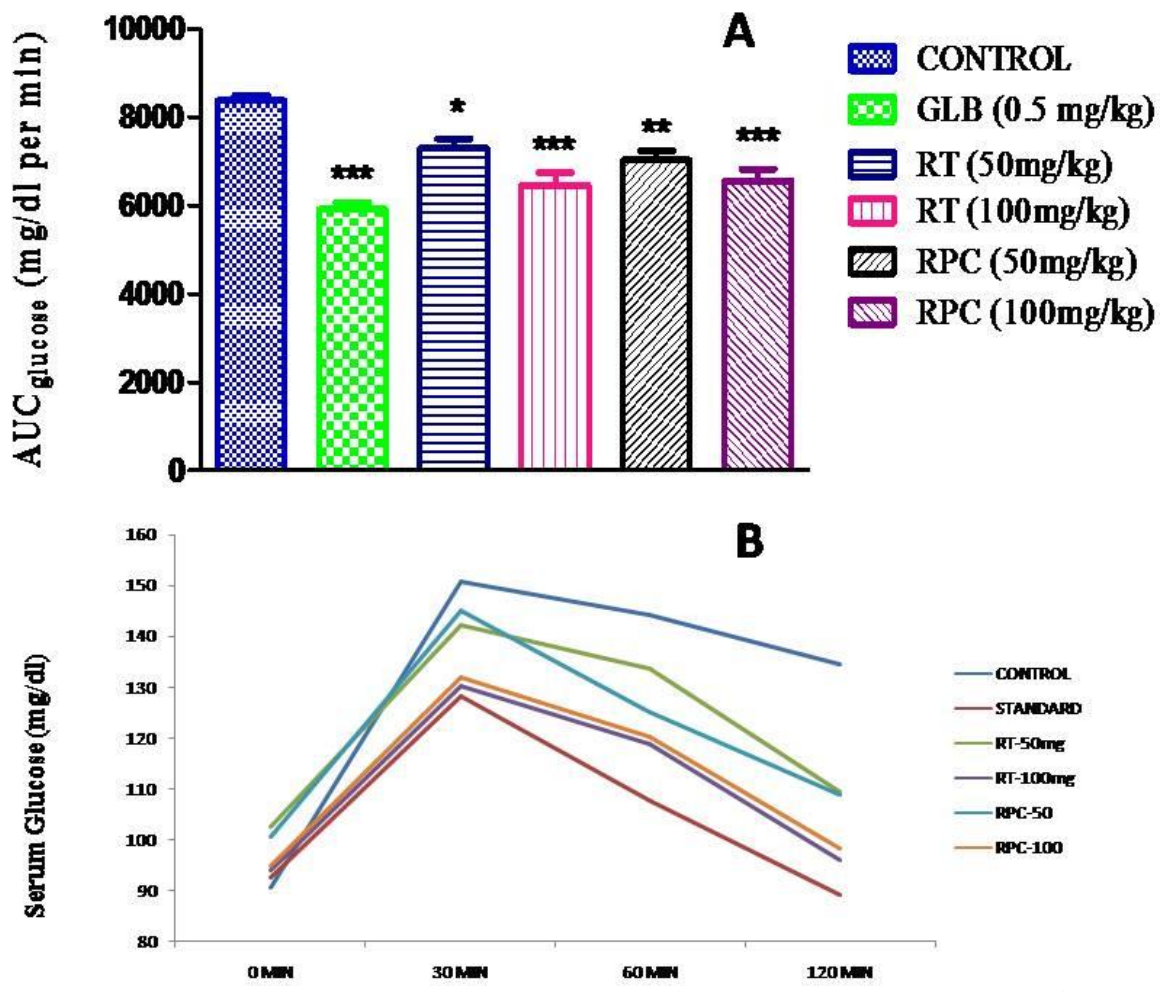

Fig. 5. A Effect of RPC in normoglycemic rats OGTT in normal rats, Area under curve for glucose (AUC glucose) values for 0-120 min post glucose load. Data represent the mean \pm S.E.M., for $\mathrm{n}=6$. $* \mathrm{P}<0.05 ; * * \mathrm{P}<0.01 ; * * * \mathrm{P}<0.001$ as compared to control. B) Serum glucose level, $\mathrm{SG}$ levels were measured at $0,30,60$ and $120 \mathrm{~min}$ after p.o. administration of glucose $(2 \mathrm{gm} / \mathrm{kg} \mathrm{b.w})$

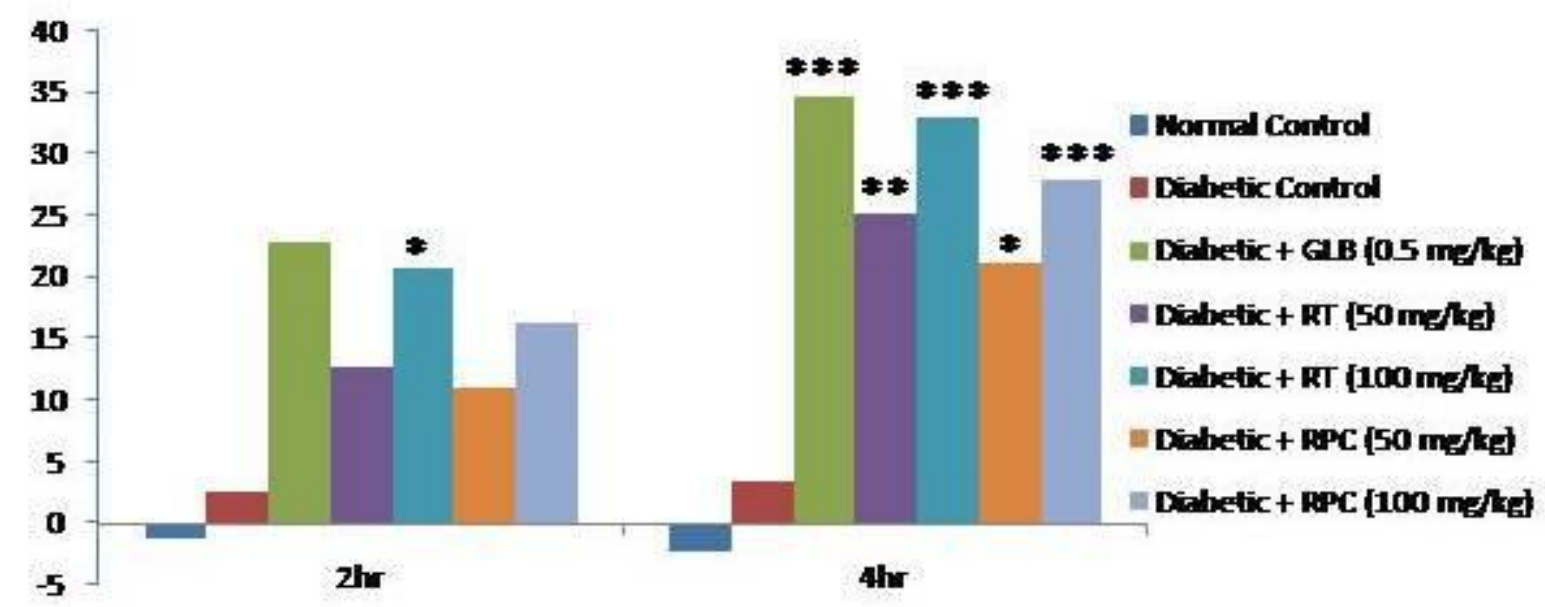

Fig. 6: Effect of RPC on STZ induced diabetic rats, Single dose single day study SG levels were measured at 0, 1, 2 and $4 \mathrm{hr}$ after single oral administration of RT, RPC and GLB. Data are expressed as means \pm S.E.M., for $\mathrm{n}=6$ rats per group. ${ }^{*} \mathrm{P}<0.05 ;{ }^{*} \mathrm{P}<0.01 ; * * * \mathrm{P}<0.001$, when compared to base values of the same group 


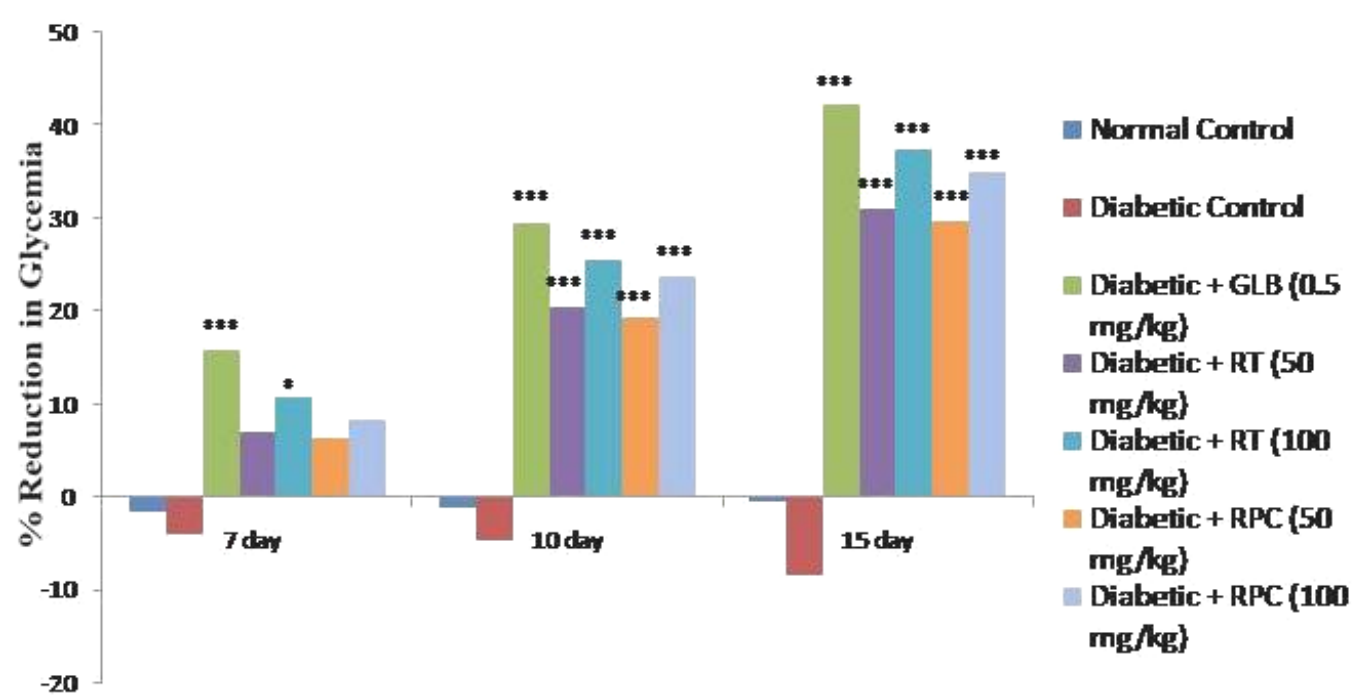

Fig. 7: Multiple dose fifteen day study, Bar graph represents the percentage reduction in glycemia with respect to the initial ( 0 day) level. Each value represents Mean \pm S.E.M., for $\mathrm{n}=6 . * \mathrm{P}<0.05, * * \mathrm{P}<0.01$, $* * * \mathrm{P}<0.001$ compared to diabetic control rats of the same time interval.

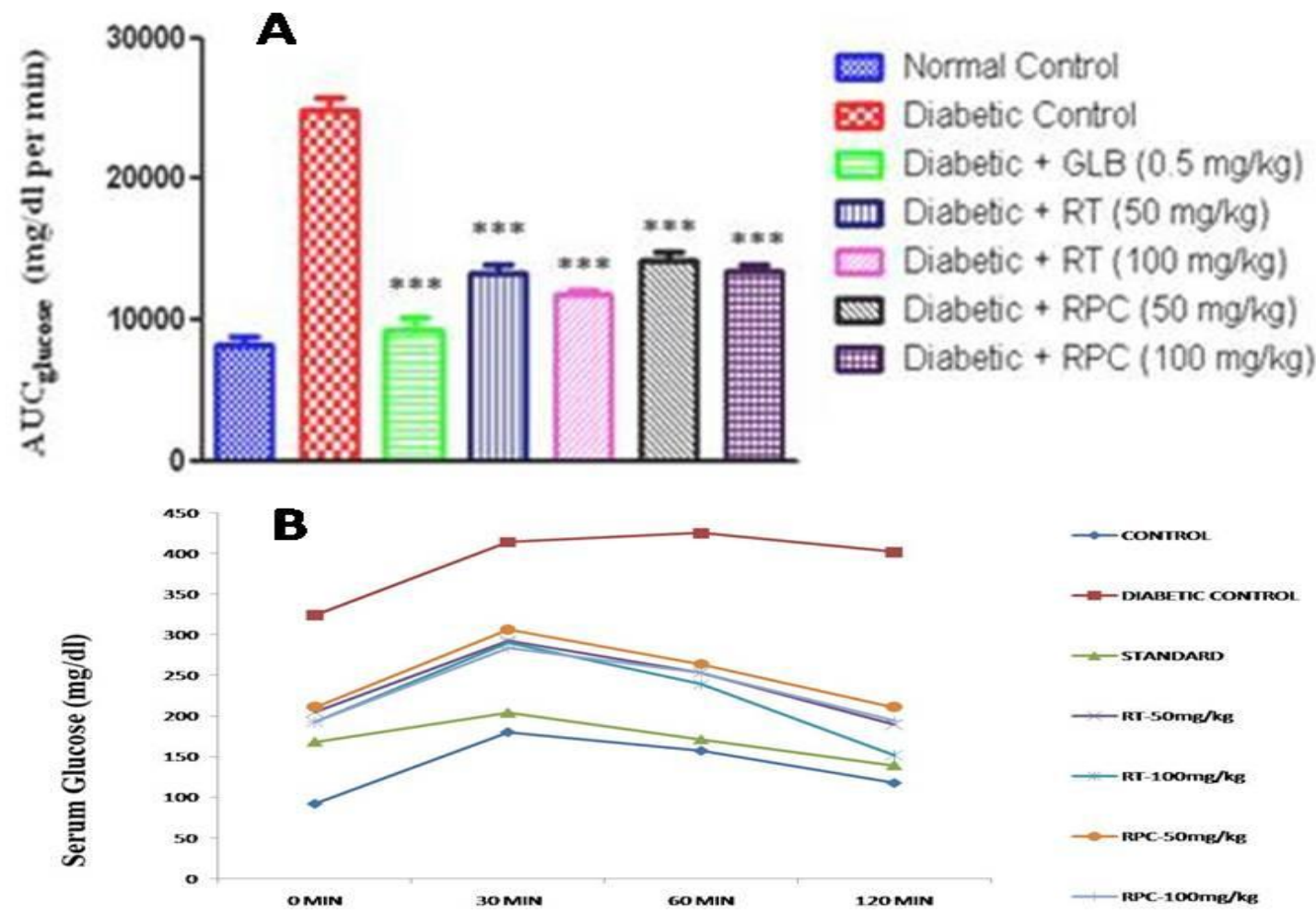

Fig. 8. A) OGTT in diabetic rats, AUC glucose values for $0-120 \mathrm{~min}$ post glucose load Data represents the mean \pm S.E.M., for $\mathrm{n}=6$. $* * * P<0.001$ as compared with diabetic Rats. B) SG levels were measured at 0, 30, 60 and $120 \mathrm{~min}$ after p.o. administration of glucose ( $2 \mathrm{gm} / \mathrm{kg}$ b.w) 

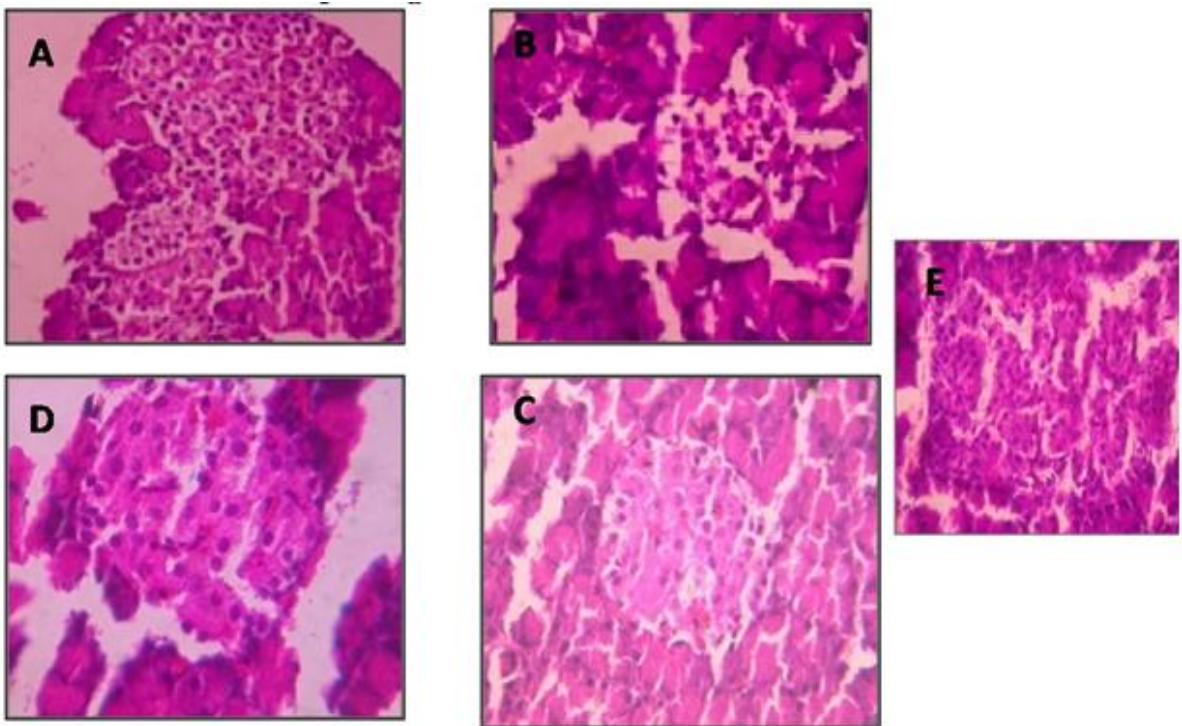

Fig. 9: Histopathological Microphotographs of rat pancreas after oral administration of RT \& RPC A) Normal, B) Diabetic, C) Glibenclamide , D) Rutin, E) Rutin phospholipid complex.

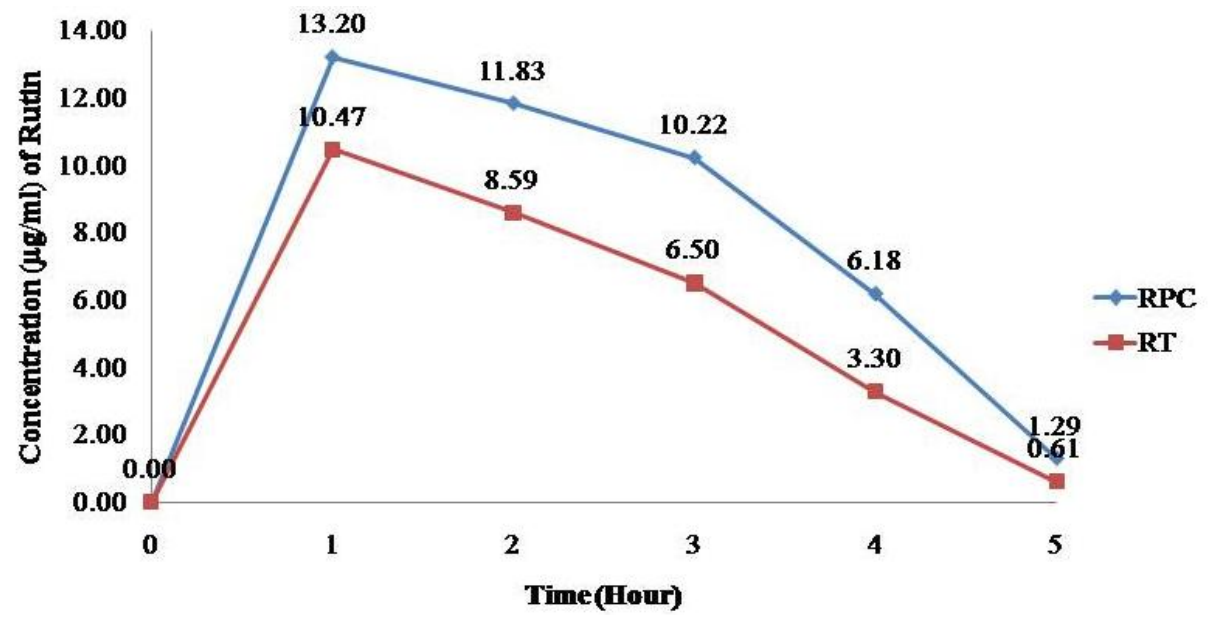

Fig. 10: Concentration of Rutin in rat serum, Serum concentration of RPC and RT in rats (n=6/groups).

\section{Bioavailability experiments in rats}

Figure 10 shows the results of serum concentration study of RT and RPC in rats. Peak serum concentration of $10.47 \mu \mathrm{g} / \mathrm{mL}$ attained rapidly within $1 \mathrm{~h}$ after the administration of pure rutin. But in case of complex, the peak concentration $13.20 \mu \mathrm{g} / \mathrm{mL}$ appeared at same time and was much higher than pure rutin. The higher concentration was also maintained for longer time before being dropped down. The entrapment of RT in HSPC molecule may therefore decrease its molecular instability to improve its effective half life, which showed that RPC was in the stable form and prevented its degradation in liver.

\section{DISCUSSION}

The function of insulin is to maintain normal blood glucose levels either by suppression of glucose output from liver or by the stimulation of glucose uptake and its metabolism. Decrease in release of insulin or loss of insulin action at target tissues causes abnormal glucose and lipid metabolism. This results in increased blood sugar level, the indication of diabetes. STZ induced experimental diabetes is a valuable model for induction of type 1 diabetes. It is generally accepted that severe diabetes (SD) is similar to type 1 and mild diabetes (MD) is similar to type 2 diabetes (Matti et al., 2005). An oral glucose tolerance test is a more sensitive measure of early abnormalities in glucose regulation than fasting plasma glucose or glycosylated haemoglobin (Singleton et al., 2003). Impaired glucose tolerance reflects hepatic gluconeogenesis and reduced uptake of glucose from blood into skeletal muscle and adipose tissue following a meal (Robertson, 2007) and impaired glucose tolerance serves as a marker for the state of insulin resistance and predicts both large and small vessel vascular complications (Tominaga et al., 1999).

Bio-flavanoids are having well-known multidirectional biological activities including antidiabetic efficacy. The biological properties of flavanoids are strictly related to their chemical structure and the choice of structural features allows the optimization of biological activities, lipophilicity, water solubility, and bioavailability. Further, it was also demonstrated that, 
bioavailability of lipophilic drugs as solid dosage forms is low, which may be due to either slow or incomplete drug release in the lumen of the gastrointestinal tract (Mukherjee, 2003). The two main reasons for this are, Firstly, these are multiple ring molecules not quite small enough to be absorbed from the intestine into the blood by simple diffusion, nor does the intestinal lining actively absorb them, as occurs with some vitamins and minerals. Secondly, flavnoid molecules typically have poor miscibility with oils and others lipids (Thurapati et al., 2011). In this case, improved drug concentration in the blood can be achieved by the use of delivery systems, which can enhance the rate and the extent of drug solubilizing into aqueous intestinal fluids. Therefore, a novel approach to increase therapeutic index of such compounds is essential for their better clinical utility. Phospholipids play a major role in the development of drug delivery systems. There are numerous advantages of phospholipids in addition to solubilizing property while considering them for a carrier system.

Development of valuable drug delivery system from natural resources is very much necessary because of beneficial role of herbal drug in the management of varied diseases. The present research is very much essential to explore the therapeutic efficacy of the natural molecules and to develop the proper delivery system to enhance the therapeutic potential of those molecules (Mukherjee, 2003). The application of novel drug delivery systems (NDDS) and polymer science especially the natural polymers started a new era in enhancing the clinical efficacy of the phytochemicals/extracts which are known as phytosomes.

In the present experiment we prepared rutinphospholipid complex by a simple and reproducible method. The physicochemical investigations showed that rutin formed a complex with phospholipids. The complex has enhanced $n$-octanol solubility. The FTIR spectra revealed shifting of $\mathrm{OH}$ group to lower frequency in RPC spectra as compared to RT and either phospholipid, indicating the formation of strong hydrogen bond between hydroxyl groups of phospholipids and the RT in the phytosome form. The band of both long chain fatty acids in the phospholipid molecule of phytosome spectra is maintained unchanged, which shows that the long chain are not involved in phytosome formation.

DSC of phospholipids complex shows the endothermal peaks of drug and phospholipid are disappeared and the phase transition temperature is lower than the phase transition temperature of phospholipids, it was considered that rutin and phospholipids should have some interaction, such as hydrogen bonding or van der Waals force. The antidiabetic activity of the complex was significantly higher than pure rutin in all dose levels tested. The present data suggested that RT and RPC significantly reduced hyperglycemia in both single dose one day and multiple dose fifteen day diabetic studies. The efficacy of RPC is better than RT which is mediated by improving the glycemic control mechanisms (extra pancreatic) and increasing insulin secretion from remnant pancreatic b-cells in diabetic rats.

The RT and RPC supplementation also results in significant attenuation in STG, STC, VLDL-c and LDL-c. These effects may be due to low activity of cholesterol biosynthesis enzymes or low levels of lipolysis. Increased TC/HDL-c and LDLc/HDL-c ratios are well known markers of dyslipidemia in STZ induced diabetic rats (Thurapati et al., 2005). RT and RPC administration reinstated dyslipidemic markers to near normal values.

The enhanced therapeutic efficacy of RT in terms of antidiabetic, obtained from RPC may be due to better absorption and bioavailability of the molecule. The exact mechanism behind the improved therapeutic efficacy of RPC requires further investigations of pharmacokinetic parameters to support the claim of better absorption and enhanced bioavailability.

\section{CONFLICT OF INTEREST STATEMENT}

We declare that we have no conflict of interest.

\section{ACKNOWLEDGEMENTS}

Authors are thankful to Rajiv Gandhi University of Health Sciences, Bangalore for financial support to carry out this work. Authors also thank President, Soniya education trust, and Principal SET's college of pharmacy, Dharwad for providing necessary facilities to carry out this research.

\section{REFERENCES}

Chi Yu Yang, Su Lan Hsiu, Kuo-Ching Wen, et al. Bioavailability and metabollic pharmacokinetics of Rutin and Quercetin in Rats. J of food and drug analysis, 2005; 13(3): 244-250.

Friedewald WT, Levy RI, Fredrickson DS. Estimation of lowdensity lipoprotein cholesterol in plasma, without use of the preparative centrifuge. Clin Chem, 1972; 18: 499.

Galigher AE, Kozloff EN. 1971. In: Essentials of practical microtechnique, 2nd edn. Lea and Febiger, Philadelphia, p. 77-79.

Goutam B. 2011. Bio-flavonoids with promising antidiabetic potentials: A critical survey. Opportunity, Challenge and Scope of Natural Products in Medicinal Chemistry; p.187-212.

Guariguata L, Whiting IDR, Hambleton J, et al. Global estimates of diabetes prevalance for 2013 and projections for 2035. Diabetes research and clinical practice, 2014; 103(2): 137-149.

Kidd PM. Bioavailability and activity of phytosome complexes from botanical polyphenols: the silymarin, curcumin, green tea, and grape seed extracts. Altern Med Rev, 2009; 14(3): 226-46.

Kumar GPS, Arulselwan P, Kumar DS, et al. Anti-Diabetic activity of Fruits of Terminalia chebula on Streptozotocin Induced Diabetic Rats. J Health Sci, 2006; 52(3): 283-91.

Liu X, Dong M, Chen X, et al. Antioxidant activity and phenolics of an endophytic Xylaria sp. from Ginkgo biloba. Food Chem, 2005; 105: 548-54.

Maiti K, Mukherjee K, Gantait A, et al. Curcumin-phospholipid complex: therapeutic evaluation and pharmacokinetic study in rats. Int $\mathrm{J}$ Pharm, 2007; 330 (1-2): 55-163.

Matti R, Das UK, Ghosh D.Attenuation of hyperglycemia and hyperlipidemia in streptozotocin induced diabetic rats by aqueous extract of seed of Tamarindus indica. Biol. Pharm.Bull, 2005; 28:11721176.

Mukherjee PK. 2003. Plant products with hypercholesterolemic potentials. In:Taylor, S.L.(Ed), Advances in food and Nutrition Research.Elsevier Academic Press, New York, p. 277-338.

Muruganandan S, Srinivasan K, Gupta S, et al. Effect of mangiferin on hyperglycemia and atherogenicity in Streptozotocindiabetic rats. J Ethnopharmacol, 2005; 97(3): 497-501. 
Prasanna H, Ramesh K, Rashmi V. Preparation and evaluation of Bocopa- Phospholipid complex for antiamnesic activity. Drug invention today, 2013; 5:13-21.

Rajkumar M, Uttam KD, Debidas G. Attenuation of hyperglycemia and hyperlipedmia in streptozotocin induced diabetic rats by aqueous extract of seed of Tamarandus indica. Biol pharm bull, 2005; 28:1172-1176.

Robertson RP. Estimation of $\beta$-cell mass by metabolic tests: necessary, but how sufficient? Diabetes, 2007; 56: 2420-24.

Shirwaikar A, Rajendran K. Effect of aqueous bark extract of Garuga pinnata Roxb. in streptozotocin-nicotinamide induced type-II diabetes mellitus. J Ethnopharmacol, 2006; 112: 1-6.

Singleton JR, Smith AG, Russell JW, et al. Microvascular complications of impaired glucose tolerance. Diabetes, 2003; 52: 2867-73.

Thurapati P. R., Mettu, S. R. Phytosomes: a novel phytophospholipid carrier for herbaldrug delivery. Int Res J Pharm, 2011; 2(6): 28-33.

Tominaga M, Eguchi H, Manaka $\mathrm{H}$, et al. Impaired glucose tolerance is a risk factor for cardiovascular disease, but not impaired fasting glucose. The Funagata Diabetes Study. Diabetes Care, 1999; 22: 920-24.
Upendra Rao M, Sreenivasulu M, Chengaiah B, et al. Herbal Medicines for Diabetes Mellitus: A Review. Int J Pharm Tech Res, 2010; 2(3):1883-92.

Yanyu X, Yunmei S, Zhipeng C, et al. The preparation of silybin-phospholipid complex and the study on its pharmacokinetics in rats. Int J Pharm, 2006; 307(1): 77-82.

\section{How to cite this article:}

Vankudri R, Habbu P, Hiremath M, Patil BS, Savant C. Preparation and therapeutic evaluation of rutin-phospholipid complex for antidiabetic activity. J App Pharm Sci, 2016; 6 (01): 090-101. 